This article was downloaded by: [Halmstad University Library]

On: 03 April 2013, At: 23:45

Publisher: Taylor \& Francis

Informa Ltd Registered in England and Wales Registered Number: 1072954 Registered

office: Mortimer House, 37-41 Mortimer Street, London W1T 3JH, UK

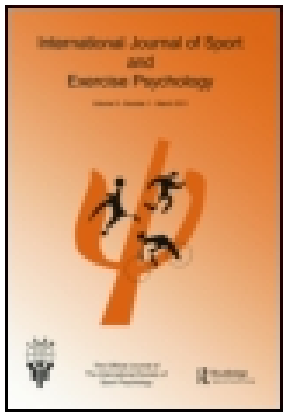

\title{
International Journal of Sport and Exercise Psychology
}

Publication details, including instructions for authors and subscription information:

http://www.tandfonline.com/loi/rijs20

\section{ISSP Position Stand: Culturally competent research and practice in sport and exercise psychology}

Tatiana V. Ryba ${ }^{\text {a }}$, Natalia B. Stambulova ${ }^{\text {b }}$, Gangyan $\mathrm{Si}^{\mathrm{c}}$ \& Robert J. Schinke ${ }^{d}$

a Department of Public Health, Aarhus University, Aarhus, Denmark

b School of Social and Health Sciences, Halmstad University, Halmstad, Sweden

c Sport Psychology and Monitoring Centre, Hong Kong Sports Institute, Fo Tan, Sha Tin, Hong Kong

d School of Human Kinetics, Laurentian University, Sudbury, Canada

Version of record first published: 03 Apr 2013.

To cite this article: Tatiana V. Ryba , Natalia B. Stambulova , Gangyan Si \& Robert J. Schinke (2013): ISSP Position Stand: Culturally competent research and practice in sport and exercise psychology, International Journal of Sport and Exercise Psychology, DOI:10.1080/1612197X.2013.779812

To link to this article: http://dx.doi.org/10.1080/1612197X.2013.779812

\section{PLEASE SCROLL DOWN FOR ARTICLE}

Full terms and conditions of use: http://www.tandfonline.com/page/terms-andconditions

This article may be used for research, teaching, and private study purposes. Any substantial or systematic reproduction, redistribution, reselling, loan, sub-licensing, systematic supply, or distribution in any form to anyone is expressly forbidden.

The publisher does not give any warranty express or implied or make any representation that the contents will be complete or accurate or up to date. The accuracy of any instructions, formulae, and drug doses should be independently verified with primary sources. The publisher shall not be liable for any loss, actions, claims, proceedings, 


\title{
ISSP Position Stand: Culturally competent research and practice in sport and exercise psychology
}

\author{
Tatiana V. Ryba ${ }^{\mathrm{a} *}$, Natalia B. Stambulova ${ }^{\mathrm{b}}$, Gangyan $\mathrm{Si}^{\mathrm{c}}$ and Robert J. Schinke ${ }^{\mathrm{d}}$ \\ ${ }^{a}$ Department of Public Health, Aarhus University, Aarhus, Denmark; ${ }^{b}$ School of Social and Health \\ Sciences, Halmstad University, Halmstad, Sweden; ${ }^{c}$ Sport Psychology and Monitoring Centre, Hong \\ Kong Sports Institute, Fo Tan, Sha Tin, Hong Kong, ${ }^{d}$ School of Human Kinetics, Laurentian University, \\ Sudbury, Canada
}

(Received 19 December 2012; final version received 22 February 2013)

\begin{abstract}
The multicultural landscape of contemporary sport sets a challenge to rethink sport and exercise psychology research and practice through a culturally reflexive lens. This ISSP Position Stand provides a rigorous synthesis and engagement with existing scholarship to outline a roadmap for future work in the field. The shift to culturally competent sport and exercise psychology implies: (a) recognizing hidden ethnocentric philosophical assumptions permeating much of the current theory, research, and practice; (b) transitioning to professional ethics in which difference is seen as not inherent and fixed but as relational and fluid; and (c) focusing on meaning (instead of cause) in cross-cultural and cultural research projects, and cultural praxis work. In the paper, we first provide an overview of the concepts of cultural competence and ethics of difference. Second, we present a step-by-step approach for developing a culturally competent project rooted either within cross-cultural or cultural research. Third, we focus on cultural praxis as a project that blends theory, research, and lived culture of practice. Finally, we summarize main points in nine postulates and provide recommendations for enhancing cultural competence in the field of sport and exercise psychology.
\end{abstract}

Keywords: cross-cultural psychology; cultural psychology; cultural praxis; culturally competent researcher; culturally competent practitioner

Cultural diversity is an important challenge that is frequently encountered by sport and exercise psychology professionals. Increased globalization has fostered a wider exchange of people, objects, images, ideas, value systems, and information, which has thus changed the contemporary sporting landscape, signifying one of the most exciting and challenging movements in the globalized cultural field today. As Urry (2000) proposed, cultures travel with and through diverse mobilities, transforming social relations, people's identities, and daily practices within and across global and local communities. Intensified border-crossing activities bring athletes, coaches, and sport psychology professionals from diverse cultural backgrounds in close contact with each other, and their individual life narratives are likely to invoke different historical memories, interpretations, and sociocultural positioning.

While sport psychology researchers do not contest that sport is a multicultural context, they often regard it from the unchallenged position of an ethnocentric (white, male, heterosexual, middle-class) way of knowing (Gill, 1994; Hall, 2001; Krane, 1996; Krane \& Baird, 2005; Parham, 2005; Ryba \& Schinke, 2009; Ryba \& Wright, 2005; Schinke \& Moore, 2011). The

\footnotetext{
*Corresponding author. Email: ryba@sport.au.dk
} 
evidence of this, following three decades of critical interventions initiated by feminist scholars in our field (see a special issue of The Sport Psychologist edited by Gill, 2001), is apparent in sport psychology research largely because it continues to be about the "universal" athlete, making readers infer participants' background from the authors' affiliations (for reviews, see Kamphoff, Gill, Araki, \& Hammond, 2010; Ram, Starek, \& Johnson, 2004). Yet, identifying athletes within broad categories constructed as oppositional binaries (male/female, straight/gay, white/“other") is similarly problematic because everything in each category is assumed to be the same. Not only does constructed sameness subvert differences within each category, binary relationships are hierarchical, signifying that one term in the oppositional binary is dominant and normative in its meaning. This is known as "the dilemma of difference" (Manow, 1984 as cited in Scott, 1994, p. 289). Manow contended that both ignoring and emphasizing difference creates a risk of recreating it in existing power relations. Therefore, a new way of thinking about athletes (and indeed sport psychology professionals) is needed - one which stresses the diversity and complexity of sport and exercise participants' behaviours and motivations through an enhanced understanding that their experiences are always contextually contained within socially and culturally available resources to make sense of the surrounding reality, including who they are and how they relate to others.

In this position stand, the objective is to outline a conceptual framework for delineating culturally competent projects and the formulation of postulates, which can guide actions towards culturally competent research and practice in sport psychology. The following discussion consists of four parts. First, we provide a brief overview of the concepts of cultural competence and ethics of difference. Second, to contextualize our discussion in the study of culture in psychology, we present a step-by-step approach for developing a culturally competent project rooted either within cross-cultural or cultural research. Third, we focus on cultural praxis as a project that blends theory, research, and lived culture of practice. Finally, we summarize the main points and provide recommendations for enhancing cultural competence in the field of sport and exercise psychology.

\section{Cultural competence and ethics of difference}

Calls for cultural competence in psychology are not new and have been linked to concerns for effective and ethical delivery of psychological services to culturally diverse clients (e.g. Andersen, 1993; Butryn, 2002; Gill, 1994, 2007; Martins, Mobley, \& Zizzi, 2000; Si, Duan, Li, \& Jiang, 2011; Terry, 2009). Recognizing that many psychological concepts and theories stem from a Euro-American context and, therefore, carry Eurocentric cultural assumptions, the American Psychological Association (APA) developed multicultural guidelines that were adopted in 2003. The APA framework emphasized three general areas: (a) cultural awareness - understanding of one's own culturally constituted beliefs, values, and attitudes; (b) cultural knowledgeunderstanding and knowledge of other worldviews; and (c) cultural skills - use of culturally appropriate communication and interventions. The guidelines conceptualize cultural competence within the American discourse of mental health stressing that service providers (including service agencies and organizations) should focus on "the client within his or her cultural context, using culturally appropriate assessment tools, and having a broad repertoire of interventions" (American Psychological Association, 2003, p. 390). Summarizing multicultural perspectives in professional practice, Martin and Vaughn (2007) referred to cultural competence as the ability to recognize difference and interact effectively with people of different cultures.

In our field, the theoretical, methodological, and political engagement with issues of sociocultural difference, identity, power, reflexivity, and praxis has become visible primarily due to ongoing, dedicated work of critical scholars. The publication of Schinke and Hanrahan's 
(2009) edited text, Cultural sport psychology, might be considered evidence that cultural sport and exercise psychology is a recognized area. Ryba, Schinke, and Tenenbaum's (2010) edited volume, The cultural turn in sport psychology, is based on a critical cultural studies approach to challenge readers to examine culture in all areas of sport and exercise psychology. Responding to that challenge, the edited collection of Stambulova and Ryba (2013a), Athletes' Careers Across Cultures, examines athlete career research through a theoretical lens of the cultural turn, exploring how social and cultural discourses within and across national boundaries shape career development and assistance. In professional practice of sport psychology, Parham's (2005) efforts in developing multicultural guidelines as well as Andersen's (2005, also Gilbourne \& Andersen, $2011)$ and Gill's $(1994,2007)$ critical reflections on sport psychology supervision and service provision should be acknowledged. The Journal of Clinical Sport Psychology special issue (Schinke \& Moore, 2011) on culturally informed sport psychology is a recent example of the ongoing debates over definitions and models of cultural competence, further highlighting challenges and controversies not only in various philosophical aspects of the concept, but also in progressing from a definition to the delivery of a culturally competent research and practice.

Stemming from the aforementioned groundwork ${ }^{1}$ and drawing further on the ISSP Competencies Position Stand (Tenenbaum, Papaioannou, \& Samulski, 2003), we consider competency as encompassing both the process and the outcome of meeting a certain expected level in the domain's knowledge base and practice standards. The knowledge base comprises theories; research methodologies; measurement, assessment, and interpretation; and ethics. The practice standards include interventions and communications. We suggest approaching areas of competence identified by Tenenbaum et al. as the sites of critical scholarly engagement, through which researchers and practitioners can probe into the invisibility of ethnocentric assumptions that structure everyday sport and exercise psychology practices. By increasing their analytical ability to recognize philosophical assumptions underpinning research traditions in psychology while considering their own sociocultural constitution and positioning, sport and exercise psychology professionals will be better equipped to develop a culturally competent project. Therefore, we see our main task in unearthing the hidden philosophical assumptions, which permeate much of the current theory, research, and practice in sport and exercise psychology.

Inherent in our task are ethical considerations to illuminate power relations operating through the construction of difference in Eurocentric discourses, in which whiteness "can be interpreted as encompassing non-material and fluid dominant norms and boundaries" (Garner, 2007, p. 67). Jean Pettifor, a leading author on professional ethics and feminist practice in international psychology, urged psychologists to recognize power and politics as forces that determine ethical behaviour. She argued that ethical principles should be viewed as values within a particular social and cultural context, warning against imposing one's own ethical standards on the rest of the world (Pettifor, 1996, 2001, 2004). When difference is constructed as inherent and fixed, it is often done on the basis of racist and/or ethnocentric discourses (Weedon, 2004). However, difference can also be constructed as relational, constituted, and fluid. As Brah (1996) astutely argued, "it is a contextually contingent question whether difference pans out as inequity, exploitation and oppression or as egalitarianism, diversity and democratic forms of political agency" (p. 126, original emphasis). In this Position Stand, we advocate for addressing cultural difference as a form of ethical and moral engagement with collective and individual subjectivities that do not yet share the privileged sociocultural space of dominant discourses.

\section{Culture as a scientific paradigm}

In this section, we take a crude paradigmatic approach to the study of culture in our discussion of the shift in psychology from an emphasis on cause to one on meaning, as reflected in 
theoretical and methodological lines of enquiry in cross-cultural and cultural psychology research. While we do not ground cultural competence within a specific paradigm, we believe culturally competent researchers and practitioners should be able to understand different assumptions underpinning cross-cultural and cultural psychology, respectively. Hence, we suggest that a culturally competent project can be designed as a cross-cultural study, a cultural study, and cultural praxis.

The Kuhnian concept of the paradigm as "universally recognized scientific achievements that for a time provide model problems and solutions to a community of practitioners" (Kuhn, 1962, p. viii) has also been explained as universally accepted theory about how the world works. Theories are embedded in a particular view of the social world providing a structure as to how we understand certain phenomena and relationships. If we believe that an objective perception of reality is theoretically possible, then employing a model or framework that maps the world as it really is, and which offers an explanation of the laws of human behaviour would be intuitively appropriate. In contrast, if we hold a position that knowledge of the world is fragmented, relational, and situated, then we approach theory as a cultural artefact that offers an insight into the meaning system, which allows us to make situated knowledge claims. As Kuhn elucidated, shared assumptions and standards for scientific practice are necessary for the continuation of a particular research tradition.

Cross-cultural psychological studies operate within a positivist epistemological paradigm employing modernist theories to derive and test research hypotheses. Positivism is a philosophical stance that assumes the independent existence of an objective reality that can be revealed by means of careful and bias-free observation. Hence, for cross-cultural researchers culture is an external entity, "theorized as an independent variable and assumed to influence the psychological functioning of individuals" (O’Dell, de Abreu, \& O’Toole, 2004, p. 138). Culture is used to indicate some type of belonging to a group, usually based on a geographical location or linguistic identification, and is used further as a basis for comparing psychological aspects of performance across national samples. This is known as an etic perspective on culture (Ponterotto, 2005).

Cultural psychology was launched in response to the dissatisfaction with the ontological universalism and decontextualized methodology of cross-cultural studies. The main concern of cultural psychology is with how culture underpins the psychological processes and is embedded in socio-historical contexts (Miller, 2002). Hence, for cultural researchers, there is no separation between subject and context as they "live together, require each other, and dynamically, dialectically, and jointly make each other up" (Shweder, 1990, p. 1). Given the theorized interdependence of psychological and sociocultural, mental processes and behaviours are not merely influenced, but constituted by varied cultural discourses and material practices. Cultural psychologists take a cultural insider perspective, known as the emic view of culture, emphasizing the importance of language, communication, relational perspectives, cultural practices and meanings, beliefs, and values in human development. The focus of cultural research, therefore, is on the interpretive analysis of culture in search of meaning (Geertz, 1973), using theory as a fluid heuristic (rather than a fixed model) through which individual experiences can be interpreted.

Next we explicate the paradigmatic differences in cross-cultural and cultural psychology by presenting a step-by-step approach to developing a culturally competent sport psychology project rooted either within cross-cultural or cultural research. Within each design, we briefly explain the research goals; how culture is studied, described, and interpreted; and researcher axiological positioning. We also provide a research example to bring to life some of the conceptual and methodological arguments. 


\section{Cross-cultural research}

\section{Research goals}

Cross-cultural psychology can be regarded as the testing of "the boundaries of knowledge about human behaviour by comparing it in two or more cultures" (Matsumoto \& Jones, 2009, p. 323). In cross-cultural research, the systematic comparison of psychological variables under different cultural conditions is performed in order to "determine the limits within which general psychological theories do hold, and the kinds of modifications of these theories that are needed to make them universal" (Triandis, Malpass, \& Davidson, 1973, p. 1). Such definition gives a clear goal for cross-cultural research in psychology (see also Spering, 2001).

\section{How do we study culture in cross-cultural psychology?}

Cross-cultural studies are typically quantitative in design. As stated by Van de Vijver and Leung (1997), there are four common types of cross-cultural studies as follows: (a) generalizable (i.e. with hypothesis, but no contextual consideration); (b) theory-driven (with both specific hypothesis and contextual consideration); (c) psychologically differentiable (with neither hypothesis nor contextual consideration); and (d) externally valid (with no hypothesis, but contextual consideration exists). Across all four types of studies, there is always an issue of borrowing/adapting the questionnaire or psychological instrument across cultures. Standard procedure of instrument adaptation, psychometric validation and interpretation is described next.

Translation methodology. Based on the revision of Brislin, Lonner, and Thorndike (1973) and International Test Commission (ITC, 2010) Guidelines, Ægisdóttir, Gerstein, and Cinarbas (2008) summarized recommended translation practices. Relevant, sequenced recommendations from that summary for this position stand-regarding the borrowing of instruments from one culture to another - are extracted as follows. There should be: (1) independent translation from two or more persons familiar with the target language, culture, and intent of the instrument; (2) documentation of comparisons of translations and agreement on the best translation; (3) rewriting of translated items to fit the grammatical structure of the target language; (4) independent back-translations of translated versions into the original language; (5) comparison of original and back-translated versions, focusing on appropriateness, clarity, and meaning; (6) changes to the translated version based on comparison until satisfactory; and (7) pre-testing of translated instruments on an independent sample (e.g. $N=10$ ) to check for clarity, appropriateness, and meaning for each item.

Analysis (preliminary and equivalence). Cronbach's alpha reliability, item-total scale correlations, and item means and variation indicate the initial psychometric properties of translated instruments (Ægisdóttir et al., 2008). A significant difference in reliability coefficients between two independent samples may indicate item or construct bias. Item-total correlation may indicate construct bias (e.g. differential social desirability and differential familiarity with instrumentation). Although these issues are more related to cross-cultural comparisons, researchers/practitioners are recommended to beware of them when borrowing instruments.

Exploratory and confirmatory factor analysis, multidimensional scaling techniques, and cluster analysis can be used to investigate construct and measurement-unit equivalence of translated instruments (Van de Vijver \& Leung, 1997). These methods help the researcher to see if the construct is structurally and meaningfully similar in both target and original cultures. It is always difficult to establish full scalar equivalence. Van de Vijver and Leung suggested that full score comparability, intra-cultural validation (i.e. comparison with theoretical expectation), and 
cross-cultural validation are three main approaches of establishing scalar equivalence and are important even for researchers/practitioners not interested in cross-cultural comparison, because researchers may rely on the theory/model/structure developed from original culture to interpret the data collected in the targeted culture.

\section{How do we describe culture? (Interpretation)}

When full equivalence and bias are established, the translated instruments can be employed with the assumption that the construct, which is being tested, is similar to the originally designed conceptualization. It is, however, quite difficult to establish completed scalar equivalence. Therefore, researchers/practitioners are recommended to be aware of the possible covariates or meaning of the relevant constructs within the targeted culture, and to conduct "unpackaging studies" that examine the degree to which the context variables statistically account for the group differences found in the data by mediation or covariance analyses (Matsumoto \& Jones, 2009). Different cutoff points and norms may also be needed for better interpretation. To make interpretation practically meaningful, researchers are recommended to engage in effect size statistics in addition to inferential analyses, such as ANOVA, chi-square, and $t$-tests. In a broader perspective, researchers should be aware of the way they operationalize cultures. There can be statistical group differences due to operationalizing culture as race or nation, for example. Such misinterpretation of statistical group difference may lead to the cultural attribution fallacy (Matsumoto \& Jones, 2009). Ideally, researchers are recommended to engage with cultural informants from the outset of the project to avoid cultural bias when interpreting research findings. Additional information can be found in the ITC (2010) guidelines for documentation and score interpretation.

\section{Researcher positioning/ethics}

There are several ethical issues associated with conducting cross-cultural psychology research, which should be considered in addition to standard ethical research practices (e.g. obtaining informed consent and ensuring participant confidentiality). One of the key principles is that the studies should not be used to vindicate powerful stereotypes about any cultural group (Matsumoto \& Jones, 2009). Researchers should consider whether their research question is worthy enough of pursuing in terms of research relevancy and contribution towards understanding human behaviour. Finally, researchers must avoid actions, procedures, and interactive styles that may violate local customs and understandings of the studied community.

\section{Cross-cultural sport psychology research example}

To exemplify cross-cultural sport psychology research, we will use the European Perspectives on Athletic Retirement Project aimed at searching for common and also nation-specific patterns in career termination and post-career adaptation of former elite athletes from Germany, Lithuania, Russia, France, and Sweden (Alfermann, Stambulova, \& Zemaityte, 2004; Stambulova, Stephan, \& Jäphag, 2007). Two project leaders (lead authors of the two aforementioned references) began the research endeavour by discussing its general idea and relevant theoretical frameworks amongst themselves. Because the project leaders were from different cultures and had different sport psychology scientific training, it was not an easy task to select one framework for developing an instrument. The compromise was found through combining two internationally recognized transition models (Schlossberg, 1981; Taylor \& Ogilvie, 1994) and the authors' own theorizing on the topic (Alfermann, 2000; Stambulova, 1994) as the basis for developing the Athletic Retirement Survey (ARS). The basic version of the ARS was created in English and then 
translated into relevant languages using to-and-from translation assisted by language experts. Translated versions were piloted in the involved countries and relevant cultural adaptations were made. For example, Russian participants were confused with the term "guest marriage" and, therefore, this marital status option was deleted in the Russian version. Further discussions were led around culturally relevant meanings of the ARS items. For example, in Sweden, "civil marriage" (called "sambo" or literally "co-living") is legally recognized as marriage, while in Russia "civil marriage" is unofficial and in the case of separation it is very difficult to solve problems regarding division of joint possessions.

After creating national versions of the ARS, the researchers explored the culturally relevant ways of data collection to get higher return rates. It appeared that postal survey worked well enough in four countries but not in Russia, where data were additionally collected through personal meetings by the relevant author and the participants. When all data were collected, basic psychometric properties of the ARS (e.g. Cronbach's alphas for all the sub-scales) were calculated and the differences between the national samples were examined using ANOVA and MANOVA. This treatment of the data allowed the researchers to identify a common pattern in European athletes' retirement (e.g. facilitating roles of retirement planning, voluntary termination, effective social support, active coping strategies) and nation-specific patterns (e.g. predominance of job-related reasons for retirement in the German sample, or searching for post-athletic careers mainly outside of sport in the Swedish sample). Interpretation involved a combination of career transition frameworks and analysis of sociocultural, historical, and sport system contexts in the relevant countries using Bronfenbrenner's (1979) model and the cultural syndromes framework (Triandis, 2004).

After the two aforementioned studies were published, Stambulova and Alfermann (2009) reflected on the lessons learned from the project as a whole, highlighting the importance of the following characteristics for future cross-cultural transition research: (a) cultural awareness and negotiations of terms and theoretical frameworks, (b) not only translation but also cultural adaptation of the instruments used, (c) culturally relevant ways of data collection, and (d) in-depth contextualization of data during analysis and interpretation. They also concluded that, in spite of treating culture as a packaged variable denoting a whole range of characteristics in national and sporting cultures in the countries involved, the European Perspectives on Athletic Retirement Project confirmed an important role of culture in athlete retirement and stimulated a culturespecific approach in assisting retired athletes.

\section{Cultural research}

\section{Research goals}

Cultural sport psychology recognizes a breadth of theoretical and methodological approaches available to investigate each sport performer, such as an approach to match more closely with Maori (Hodge, Sharp, \& Ihirangi Heke, 2011), Australian Aboriginal (Hanrahan, 2009), or Chinese (Si et al., 2011) athletes. Moreover, one must learn about the athlete's and/or coach's world while also understanding one's own position as culturally saturated (Ryba, 2009; Ryba \& Schinke, 2009; Schinke, McGannon, Parham, \& Lane, 2012), with each persona built from various intersecting characteristics that include, though are not restricted to, gender, sexuality, socio-economic status, race, ethnicity, nationality, geographic location, and dis/ability (Gill \& Kamphoff, 2010; McGannon \& Johnson, 2009; Schinke, Hanrahan, \& Catina, 2009). In contrast, an overly simplified approach, utilizing a singular characteristic or one that is generalized across a group, tends to exclude much of what constitutes cultural understanding, resulting in unethical services that do not align, nor meet the end needs of the participant. Hence, the goals through cultural research are to: (a) reveal the cultural standpoints of each sport participant, meaning not only 
"what" but also "how" a cultural identity is constituted; (b) understand the role of the researcher/ practitioner and what cultural lens s/he infuses into a project; and (c) create a transparent place for the aforementioned.

\section{How do we study culture in cultural psychology?}

Most of what has been written thus far reveals conceptual views that transcend into our conduct as researchers. One feature from these burgeoning writings is a critical response by Andersen (1993) where he correctly identified that a group of basketball players were being raced into a singular African American stereotype. What Andersen raised through his response to Lee and Rotella (1991) is that an overly simplified cultural classification cannot tell the full story of a participant's identity and its sociocultural constitution, contributing to the perpetuation of colonizing practices with a group of culturally vulnerable participants. There is no singular way to engage in a cultural method, such as a talking circle with Canadian Aboriginal sport participants (i.e. a culturally infused derivative of a focus group), just as one cannot use one conversational approach, such as sustained or averted eye contact, when interviewing a participant from any racial or national group. The approach one takes to data collection is developed through contextually relevant knowledge, partly via a priori discussion with the participant, and partly through informational cues that are conveyed from the earliest stage of the research process. Hence, one gains from Andersen's early work a clear warning to avoid sensitive stereotyping that transfers rather nicely to the conceptualization of cultural research.

White privilege and reflexivity. Since Butryn's (2002) paper, sport psychology researchers/ practitioners have begun to consider the advantaged position of being a white, mainstream sport psychologist (see also Butryn, 2010). Two of the privileges listed by Butryn include being among the racial majority in educational contexts in the USA and among the racial majority in the applied domain. To these, we add the privilege of access to sport psychology skills, including research tools that align with the researcher's cultural and educational knowledge (e.g. white, Westernized, mainstream), though perhaps not always with the participant's (Schinke et al., 2009). By turning the mirror onto himself, Butryn catalysed discussions about researcher selfawareness, reflexivity, and culturally reflexive practice. In addition, Butryn's work has opened up a research approach with the focus placed on sport psychology researchers' cultural standpoints via auto-ethnography (see Butryn, 2010; Dzikus, 2012). Researcher reflexivity into normative and, therefore, taken-for-granted whiteness has led to provision of strategies that permit the culturally infused identities of researcher and participant to be visible parts of the methodology.

How might one use these practices within research? First, it must be recognized that prevailing approaches to research are culturally saturated, and that there is a plethora of cultural approaches one might garner, leading to better conceptualized methodologies and meaningful methodological practices. Second, scholars are often invisible in the projects for which they are involved. There must be a shift from being invisible to becoming visible. Doing so would not only facilitate self-awareness and vigilance to centralize the participant's practices, it would also clarify for the reader where the researcher and participant reside in each project.

\section{How to describe culture-colonizing and de-colonizing practices}

Ryba and Schinke (2009) recently invited sport psychology authors to consider their own methodologies as a possibility for de-colonizing practices, through a special edition of the International Journal of Sport and Exercise Psychology. The authors provided methodological 
examples where previously marginalized or lesser-known voices were centralized. We will use two submissions within the instalment in this discussion. The first submission was a manuscript about how researchers sometimes cross boundaries through data collection, inserting their views and standpoints into dialogue, which turns dialogue into monologue; in a sense, colonizing participants' subjectivities (Smith, Collinson, Phoenix, Brown, \& Sparkes, 2009). Though the aforementioned piece pertains to the interviewing process, boundary crossing can also be applied to how a culture is described, who is doing the describing, and who is the rightful authority. In his invited Diversity Lecture at the Association of Applied Sport Psychology Conference, Wright (2007) contemplated how ethnography in the early 20th century positioned the white scholar as omnipotent and objective, and local Indigenous cultures as exotic. When scholars from outside a cultural group try to peer inside that group, they tend to cross boundaries, constituting the participant's world through the investigator's lens. The second submission by Schinke, Peltier, et al. (2009) featured a Canadian mainstream scholar and a Canadian Aboriginal community member engaging in collaborative research. These two authors dialogued about the colonizing practices of the first author and how these practices were eventually corrected, leading to a better cultural understanding. There is at least one prevailing message when describing culture: the authorities are those from within the context, not outsiders. The challenge lies in how we can recruit cultural guides before conceptualizing cultural psychology research and, once they are recruited, how these people can be encouraged to take their rightful position as authorities.

\section{Ethics through cultural psychology research}

Throughout this section, the authors have adopted a cultural psychology lens when considering research practices. How sport psychologists conceptualize and then engage in cultural psychology research clarifies whether the approach is ethically sound. There are many standards articulated for ways to conduct research in various cultural settings. These guidelines may or may not be known to university research ethics boards. However, when one engages in cultural psychology research, some of the focus is placed on social justice (Krane, Waldron, Kauer, \& Semerjian, 2010; Ryba, 2009; Ryba \& Wright, 2005, 2010). There are socially unjust ways of engaging in cultural psychology research, and we have articulated these practices above, including sensitive stereotyping, omitting one's privileged position as a researcher, and utilizing methodological approaches that silence and omit cultural practices relevant within the specific context where the investigation is taking place. In contrast, when one engages in socially just research, the marginalized voices and cultural practices are centralized (Schinke, Watson, Enosse, Peltier, \& Lightfoot, 2010). There is an emerging area of sport scholarship termed sport for development and peace. The focus in this scholarship has often been placed on applied community programmes for people in need (Schinke \& Hanrahan, 2012). However, it has been proposed that collaborative sport psychology research undertaken with community stakeholders can also create a socially just context. How can ethical cultural psychology research and practice within the domain of sport be undertaken? The solution is to reposition scholarly voices and practices in order to ensure that the appropriate cultural practices are centralized. The idea of engaging in ethical research is a reasonable and logical supposition. However, it might also be relatively challenging for voices accustomed to authoritative roles to relinquish the power position to the rightful delegates. There are various formats of scholarly knowledge, with some derived in academic silos, and some not.

\section{Cultural psychology research: an example}

This example is from Schinke's collaborative project with members of the Wikwemikong Unceded Indian Reserve in Canada. In the third year of their research collaboration, Schinke 
and colleagues received an invitation from the co-researchers of a local Aboriginal community to co-develop a new project. The topic proposed by the Aboriginal community members was for the culturally mixed team to examine the barriers to sport and recreation offerings on their Aboriginal reserve. It was believed that by understanding what barriers existed to youth engagement, the community would develop better sport programmes and a more active and engaged youth. The Wikwemikong community then decided what sort of research context would be used to gather the project data. Community feasts were chosen to begin each day of data collection, followed by cooperative games, transitioning into talking circles (an Indigenous strategy for sharing community views and resolving community challenges akin to focus groups). Even though the researchers were accustomed to gathering project data, the discussions needed to be led by community members for a few reasons. First, the topic was highly personal for the community members, given that it addressed their local challenge. Second, the methodological approach adhered to local cultural teachings, including the passing of a pouch of tobacco from person to person, with the tobacco signifying one's right to speak, the circle working clockwise, and the circle only ending when there was nothing left to be said as opposed to conventional timelines. Third, the Wikwemikong and the white researchers understood the colonizing implications of having white scholars leading research when that research featured Indigenous practices.

Once the words of the Wikwemikong were gathered through separate talking circles, the analysis was undertaken on the territorial lands of Wikwemikong. The project was about Wikwemikong, and all that was to be learned from the project needed to happen on territorial lands, where the power and privilege centralized the Wikwemikong. During three years of monthly trips, the team discussed the most recent transcripts and what these were teaching them about their community challenge. Where, initially, the white researchers tended to be the most vocal contributors to the discussion, after five or six meetings, they learned to wait in silence as the Wikwemikong co-researchers chose their words and couched each new finding in a teaching and a life story. For example, during one meeting, one of the two elders in the project team paused - she seemed satisfied with all that was being discussed, and also by the more audible voices of her community team members. She began almost inaudibly and told a story about when she was an elementary school teacher on the reserve's territory. She recalled white researchers standing in the hallways of the school, uninvited, observing her students, as if they were observing animal specimens. The story was framed as a counterpoint to the collaboration in the team's project.

The project culminated with several deliverables that the Wikwemikong wished for. One of the deliverables was the co-authoring of a vignette story by the community co-researchers. The vignette is presently being used in Wikwemikong as a teaching for emerging community researchers and those who wish to work with them. Second, the project developed into a youth leadership manual and a six-day canoe excursion up a traditional fur trade route, with the excursion ending on the shores of Wikwemikong. This final deliverable was, at first, funded through a research grant, but presently it is funded and governed by Wikwemikong - the community's preference.

So what does the reader find in the brief case example above? First, the project team attempted to integrate local Indigenous practices, so as to avoid one general Indigenous approach. Second, there were deliberate attempts at ongoing consultation, with these consultations led by the Wikwemikong community and its designated co-researchers. The methodology could be argued as a local Aboriginal approach. This approach centralized previously marginalized voices as the authorities. Third, there were ongoing efforts on the part of the white researchers to support the voices and views of the Wikwemikong as the authorities and, thus, also support the relegation of their own position. Fourth, the Aboriginal co-researchers became much more vocal of their views as the project developed. The Wikwemikong were always authorities of their own experiences, but they and their white academic co-researchers did not centralize this authority until part 
way through the project. The after effects of the project, beyond what was mentioned above, have included several of the Aboriginal co-researchers returning to university and gaining a graduate education, and of equal importance to Wikwemikong, the community are now leading their own funded research, sometimes with, and sometimes without, the support of white scholars.

\section{Towards cultural praxis}

Cultural praxis, introduced in sport psychology by Ryba and Wright $(2005,2010)$, is "a critical discourse" and "an attempt to broaden the epistemological spectrum of theory and practice in the field" (2010, p. 3). This approach is based on the cultural studies as praxis model and designed to unpack complex multidisciplinary issues relevant to individuals, groups, and societies as cultural agents. Therefore, cultural praxis challenges culture-blind theories, research, and practice, and it moves the sport psychology field from decontextualized knowledge to a new way of thinking about athletes and coaches as constituted by various discourses of race, ethnicity, gender, generation, sport events, and the national sport system, leaving their "prints" on sporting people's identities, experiences, values, and behaviours. Theory, research, and practice that are united and permeated by culture are quintessential for the cultural praxis approach, and this stimulates sport psychology professionals to deal with issues of marginalization, representation, and social justice through theory, research, and applied work.

\section{Application: cultural praxis of athletes' careers}

The evolution of understanding the role of culture in sport psychology can be associated with three steps in the system's approach, and applicable in investigations of any complex research object or a system (e.g. athletic performance, athletes' careers, coaching, and sport teams). According to the system's approach (Ganzen, 1984), the first investigation step is rough synthesis providing a general description just to learn about the system as a whole with its major components and structure. The second step is analysis focusing on the system's details, patterns, complexity, diversity, and internal/external factors involved to understand its variations, nuances, and development. The third step-synthesis of a higher level-implies a new integration of knowledge in which variations and nuances are incorporated into the holistic view, and make meanings of the system the most visible.

The aforementioned steps in understanding complex sport psychology phenomena were recently applied to analyse an evolution in the career development and transition topic (Ryba \& Stambulova, 2013; Stambulova \& Ryba, 2013b). The authors pointed out that the rough synthesis has been achieved in studying athletes' careers based on the universalist research approach. These studies played an important role in creating a current understanding of athlete career stages and transitions (see Stambulova, 2012 for a meta-review). But such general understanding has rarely been congruent with the rapidly transforming world of national and international sports, and stimulated the turn to culture. Ryba and Stambulova (2013) traced the evolution of cultural awareness in career research and assistance using waves as a metaphor. The first two cultural "waves" identified in career research-the cross-cultural and the cultural mindset-were clearly relevant to the analysis, and the international literature demonstrated diversity and different foci in career research and assistance derived from different countries (Stambulova, Alfermann, Statler, \& Côté, 2009; Stambulova \& Ryba, 2013a). Based on overviews of career research and practice in 19 countries included in the ISSP book Athletes' Careers Across Cultures, Stambulova and Ryba (2013a) identified a need for the third cultural praxis wave. Utilizing this third wave - career researchers and practitioners can approach the task of synthesizing to a higher level, integrating athlete career research and assistance under the cultural praxis paradigm. 
This new approach termed the cultural praxis of athletes' careers (Stambulova \& Ryba, 2013b) is articulated as a set of challenges for career researchers and practitioners to consider in relation to career theories, research, and assistance as permeated by culture and united into cultural praxis. More specifically, the cultural praxis of athletes' careers implies: (a) merging of the holistic lifespan (Wylleman \& Lavallee, 2004) and holistic ecological (Henriksen, 2010) perspectives in career research and assistance; (b) reflexive situatedness of career projects in relevant sociocultural and historical contexts; (c) an idiosyncratic approach in career research and assistance with specific attention to diversity in career patterns/trajectories including marginalized athletic populations; (d) an increased attention to transnationalism in contemporary sporting culture and to trans-disciplinary career research helping to grasp athletes' multifaceted lived experiences in sport and beyond; (e) multicultural and transnational consulting including international networks of existing Career Assistance Programmes; and (f) participatory action research facilitating close collaboration between researchers, practitioners, and athlete-participants. Application of the cultural praxis approach and its concretization within career research and practice can stimulate similar processes and developments in other areas of sport and exercise psychology.

\section{Cultural praxis and the scientist-practitioner model}

A cultural praxis framework blending theory, research, and practice advocates not only for culture-and-practice-informed research but also for culture-and-theory/research-informed sport psychology practice. Here a clear association with the scientist-practitioner framework widely promoted in applied sport psychology during the last decades can be found. The scientist-practitioner framework (e.g. Jarvis, 1999; Lane \& Corrie, 2006) stimulates a practitioner to also be a researcher and conduct an intervention with a client as an intervention case study involving the client's problem-setting (i.e. relevant information collection) and problem-solving (interpreting the information and helping to find the best possible solution), which is also permeated by “... a dialectic movement from action to reflection in a continuing loop" (Jarvis, 1999, p. 133). Combining the scientist-practitioner and the cultural praxis frameworks might help sport and exercise psychology practitioners to not only bridge gaps between practice, research, and theory, but also to situate themselves and their clients within certain sociocultural contexts and select the most appropriate ways of communicating and intervening with the clients. As mentioned by Ryba (2009),

When we become researchers in our practice, we keep track of two simultaneous research projects: one into construction of a problem (What information warrants further exploration?) and the other into the self (What values and experiences shape your understanding and interpretation of the problem as well as your consequent decisions?). (p. 41)

\section{Culturally competent sport and exercise psychology practitioners}

Referring to the clinical psychology literature, cultural competence is defined as "a set of congruent behaviors, attitudes and policies ... that reflect how cultural and sociopolitical influences shape individuals' worldview and health related behaviors, and how such factors interact at multiple levels of psychological practice" (Comas-Diaz, 2011 as cited in Schinke \& Moore, 2011, p. 288). We can also add that developing cultural competence is a fluid process that continuously transforms the practitioner's work. Based on the American Psychological Association (2003) Multicultural Guidelines, the ISSP Position Stand on competencies in sport and exercise psychology (Tenenbaum et al., 2003), and relevant literature in cultural sport psychology (e.g. Ryba, 2009; Ryba \& Schinke, 2009; Schinke, Hanrahan, \& Catina, 2009; Schinke et al., 2012; 
Schinke \& Moore, 2011; Si et al., 2011) three major areas of cultural competence for sport psychology practitioners can be identified. These areas (discussed in more detail below) include: (a) cultural awareness and reflexivity, (b) culturally competent communication, and (c) culturally competent interventions.

Cultural awareness and reflexivity. Schinke et al. (2009) defined cultural awareness as "a skill that can be developed with exposure to multicultural settings, sensitivity, and practice", and they suggested a list of "cultural awareness basics for sport psychology" (p. 10). These authors emphasized a need for sport psychology practitioners: (a) to account for themselves and their clients in relation to the cultures of both parties; (b) to keep in mind that view of self and the collective, gender roles, time and space are culturally bound; (c) to beware about not only between-culture differences but also within-culture variations; and (d) to understand immigrant clients' cultural adaptations as a continuum from minimum acculturation to maximum acceptance of local cultural norms, values, and behaviours. Cultural awareness can be seen as an initial step for the practitioner's cultural reflexivity about what, how, and why of what they do with their clients on the basis of each person's cultural background. This reflexivity process implies that practitioners reflect not only on the clients' backgrounds but also on their own background in a form of selfreflection. Such self-reflection in terms of how their education, ethnicity, gender, sexuality, age, and a wider breadth of possible characteristics of the cultural makeup influence their practice (e. g. approaches to problem setting and problem solving), might help the practitioner to reach alignment with the client free from cultural biases, overgeneralizations, and stereotyping. Therefore, awareness and reflexivity inform culturally sensitive and ethical communication, and interventions.

Culturally competent communication. Communication is about sending and receiving messages for the sake of motivating or influencing one's behaviour. A key question here is how to reach shared meanings with clients; otherwise, even good ideas suggested by the sport psychology practitioner might not be properly understood, accepted, and implemented. Drawing on Moghaddam and Studer (1997), Ryba (2009) brought to the attention of the sport psychology community the concept of meaningful dialogue, in which communication partners do not necessarily share the same cultural norms but rather participate in the process of searching for a sharable language that transforms the information-gathering dialogue into shared experiences. In such dialogues, the clients are welcomed to share their experiences and concerns, and the practitioners are expected to not readily provide solutions but, instead, to exchange understandings and interpretations to facilitate new insights and open new possibilities for meaning. For example, through meaningful dialogues, sport psychology practitioners might facilitate communication between athletes and coaches representing different cultures (e.g. in a sport team) to help them to be more open-minded and develop a shared "cultural code" with specific cultural elements and regulations relevant to the local setting. In some cases, to facilitate a meaningful dialogue between a practitioner and an Indigenous athlete, the athlete should be allowed to have an accompanying person representing his/her cultural community at least during the first consulting session (Hanrahan, 2004). Ryba (2009) further emphasized that meaningful dialogue has an ethical aspect shifting the role of the practitioner "from being the expert who shapes minority athletes' responses to hegemonic normative system in the name of athletic success to being a co-participant in the collaborative process of learning, reflection, critical awareness, and intervention" (pp. 43-44).

Culturally competent interventions. Culturally competent interventions are evidence-based but, at the same time, maintain respect for and consideration of cultural characteristics 
(Schinke \& Moore, 2011). As mentioned by Si et al. (2011), contemporary sport psychology theories and applied research are developed mainly in North America and Europe, so it is important to explore their cultural validity when theories are applied to other cultures; for example, in Asia. Sport and exercise psychology interventions are mainly derived from a combination of the second wave of cognitive behavioural therapy (e.g. rational emotional behavioural therapy) and psychological skills training. There is an assumption that all clients with their irrational core beliefs can be altered by objective and rational negotiation. Rational cognition will, thus, adjust their emotion and behaviour. Applying these ideas to Chinese culture, Si et al. recommended that practitioners working with Chinese athletes consider the Chinese holistic thinking style and introvert emotional expression. It is also possible that there are cultural differences in the meaning of "objective" and "rational". Recently developed mindfulness training, regarded as the "third wave of cognitive behavioural therapy", has been widely supported and applied in Western societies. Its philosophical background, however, is rooted in Buddhist culture. Those basic ideas (e.g. mindfulness and acceptance) and methods (e.g. meditation) seem to be suitable practices for Chinese athletes. Further modification of mindfulness training (reconnecting the training model to its cultural root) may make this approach strongly compelling among Chinese athletes. Therefore, when adapting intervention techniques, the practitioner's reflexivity should circle around questions, such as: "must the technique itself be modified or might the best modification be in the area of presentation and style of delivery?" (Schinke \& Moore, 2011, p. 291). Si et al. also emphasized that when designing and implementing psychological intervention programmes, practitioners should keep in mind that one important task is to help athletes develop a deep understanding of, and active adaptation to the relevant sociocultural system as a whole. For example, Chinese sport psychologists have been digging into traditional Chinese culture in order to develop culturally specific skills, such as "harmony with differences", "doing one's best and follow the fate", "Ah Q spirit" (i.e. living with adversity), "all are Buddha" (i.e. "self-discovery and self-cultivation"), and searching for a balance between Confucianism's pro-activeness and Taoism's nature following (Si et al., 2011).

Culturally competent interventions can also be briefly characterized as: (a) inseparable from recognizing the client and the self as cultural beings, (b) free from stereotyping clients based on their belonging to particular sociocultural groups, (c) taking an idiosyncratic approach to the client, and (d) standing for social justice in sport psychology services. As explained by Ryba and Schinke (2009), "there is a distinction between being treated the same and being treated equally, with only the latter promoting cultural appreciation for all concerned, in place of a mono-cultural standpoint" (p. 266). Sport psychology practitioners delivering culturally competent practice models not only effectively help clients with their performance and development, but also promote the client's cultural safety and, thus, their wellbeing.

\section{Conclusion and postulates}

In this paper, we have considered what it means to be a culturally competent researcher and practitioner, what advantages cultural competence brings, and what the major challenges are for sport and exercise psychology researchers/practitioners who want to become more culturally competent. Below we summarize the quintessence of this paper in nine postulates.

(1) Sport and exercise psychology professionals recognize sport and physical activity as multicultural contexts but often regard them from the unchallenged position of an ethnocentric (white, male, heterosexual, middle-class) way of knowing; that is they consider athletes and exercisers as "universal" beings or stereotype them based on their belonging to particular sociocultural groups of gender, ethnicity, sexual orientation, social class, and 
type of sport, to name just a few possible characteristics. Therefore, to meet challenges related to high quality and ethical research as well as effective and ethical delivery of psychological services with culturally diverse sport and exercise participants, a shift to a more culturally competent sport and exercise psychology research and practice is recommended.

(2) The shift to culturally competent sport and exercise psychology research and practice implies: (a) analysis and recognition of hidden ethnocentric philosophical assumptions permeating much of the current theory, research, and practice in sport and exercise psychology, (b) recognizing that power and politics determine ethical behaviour and the consideration that a shift to professional ethics in which difference is seen not as inherent and fixed but as relational and fluid, and (c) a focus on meaning (instead of cause) as reflected in theoretical and methodological assumptions of cross-cultural and cultural research, and cultural praxis. Therefore, to make the necessary changes sport and exercise psychology professionals are recommended to invest into developing/increasing their cultural competence.

(3) Cultural competence starts with considering athletes, exercisers, coaches, and sport psychology professionals as cultural beings with their idiosyncratic, but always contextually contained backgrounds and experiences. Many sport and exercise psychology professionals are intuitive or naive cultural or cross-cultural researchers lacking awareness of how all aspects of their projects are culturally infused. Therefore, in the process of developing cultural competence, it is recommended that the sport and exercise psychology professionals focus on cultural awareness (e.g. of their own culturally constituted beliefs, values, and attitudes and of hidden philosophical assumption of their own research) complemented by cultural knowledge (e.g. understanding of cross-cultural psychology, cultural psychology, and cultural praxis as well as of other paradigms), and cultural skills (e.g. cultural reflexivity, culturally informed communication, and interventions).

(4) A culturally competent research project can be designed as a cross-cultural psychology study, a cultural psychology study, and/or cultural praxis. When an etic perspective on culture is used (i.e. culture as external entity or independent variable), the project can be classified as cross-cultural even if it does not include a comparison of participants from different cultures. When an emic perspective on culture is employed (i.e. of a cultural insider inseparable from the context), the project aligns more closely with cultural psychology. Finally, and most recently, a project that blends theory/research, practice, and lived culture can be classified as a cultural praxis project. Therefore, positioning of the project in philosophical and methodological landscapes as well as in relevant sociocultural and historical contexts is strongly recommended. Researchers should also situate themselves in their projects and reflect on how their own cultural background (ethnicity, gender, educational, and athletic background) trickles into their project's planning, data collection, and interpretation.

(5) Cross-cultural research projects are usually quantitative and include a comparison of two or more culturally distinct athletic populations in terms of a set of variables. Therefore, cross-cultural projects are typically conducted by multicultural research groups. To conduct a competent cross-cultural project the following are recommended: (a) to discuss and negotiate meanings of key concepts of the project, theoretical frameworks, and the project objectives, (b) to implement the established procedure (see in the text above) of the instruments' translation and initial cultural adaptation, (c) to conduct pilot studies in all respective samples and further culturally adapt the instruments, (d) to use culturally relevant ways of data collection, (e) to interpret results keeping in 
mind psychometric characteristics of the instruments (as they validated in different cultures) and major characteristics of each cultural context involved, and (f) to provide contextualized conclusions and practical implications of the project.

(6) Cultural psychology projects are qualitative and based on various types of participant observations, interviews, focus groups and/or ethnographic approaches with theory as a fluid heuristic (rather than a model), assisting in the search and interpretation of meanings hidden in the individual experiences of research participants. To conduct a competent cultural sport psychology project, the following are recommended: (a) to recognize major dimensions of cultural identity of the project participants and how these dimensions (e.g. ethnicity, gender, sexual orientation) inform each other and the participants' lived experiences, (b) to recognize one's own cultural standpoint and relevant potential biases in understanding and interpreting meanings of the participants' experiences, (c) to implement culturally acceptable and locally convenient ways of data collection, and (d) to consider cultural insiders as authorities in the research group during all stages of the research process to foster de-colonizing/ empowering practices in and through the project.

(7) In cultural praxis projects (which always transform into practice), theory, research, and practice are united and permeated by culture in studying (and intervening into) a complex and often interdisciplinary problem. To conduct a competent cultural praxis project, the following are recommended: (a) to carefully position the project in specific sociocultural and historical contexts within a scientific discipline (e.g. sport psychology) or in the inter-/trans-disciplinary intersection, to match the research problem with appropriate theoretical, methodological, and applied discourses in sport psychology and other disciplines, (b) to critically reflect on cultural, professional, and athletic background of the involved researchers/practitioners, (c) to plan the research programme as a part of applied work, and applied work as informed by research data, (d) to incorporate meaningful dialogue aimed at searching for a sharable language with participants and facilitating their reflections, insights, and solutions related to the project, and (e) to develop/use theories as heuristic and contextualized constructions facilitating the adaptation of evidence-based intervention strategies to the participants' cultural characteristics and relevant contexts.

(8) Sport and exercise psychology practitioners, being "closer" to the clients' everyday life and lived culture, are typically more contextually and culturally informed than researchers. At the same time, working within one cultural context, practitioners often focus just on the content, the what, of the services, taking for granted culturally constituted methods of delivery, the how, of their services. Practitioners' lack of cultural reflexivity, potentially, can hinder applicability of psychology services to clients from different cultures and, thus, compromise the clients' cultural safety. Therefore, more attention by the service providers should be directed to marginalized groups of athletes and exercisers (e.g. female, indigenous, and others) as well as to transnational and immigrant sport and exercise participants for whom culturally competent support is a key.

(9) The multicultural landscape of contemporary sport and physical activity with increasing numbers of immigrant and transnational athletes, exercisers, coaches, and sport psychology professionals sets a challenge (and the necessity) to rethink sport and exercise psychology research and practice through a culturally reflexive lens. Therefore, we recommend the reader to treat this position paper in a self-reflexive manner, searching for meaningful ideas to enhance their own, culturally bounded, research and practice. 


\section{Acknowledgements}

We are grateful to the ISSP Managing Council members for supporting this Position Stand. Special thanks to those who provided feedback on an earlier draft of this paper. We are very grateful to Dr Ted Butryn as external reviewer for his insightful comments and enthusiastic endorsement of this position paper.

\section{Note}

1. Due to the limited journal space, it is impossible to acknowledge all authors whose innovative pioneering work has contributed to the development of this position statement.

\section{References}

Ægisdóttir, S., Gerstein, L.H., \& Cinarbas, D.C. (2008). Methodological issues in cross-cultural counseling research: Equivalence, bias and translations. The Counseling Psychologist, 36, 188-219. doi:10.1177/ 0011000007305384

Alfermann, D. (2000). Causes and consequences of sport career termination. In D. Lavallee \& P. Wylleman (Eds.), Career transitions in sport: International perspectives (pp. 45-58). Morgantown, WV: Fitness Information Technology.

Alfermann, D., Stambulova, N.B., \& Zemaityte, A. (2004). Reactions to sports career termination: A crossnational comparison of German, Lithuanian, and Russian athletes. Psychology of Sport \& Exercise, 5, 61-75. doi:10.1016/S1469-0292(02)00050-X

American Psychological Association. (2003). Guidelines on multicultural education, training, research, practice, and organizational change for psychologists. American Psychologist, 58, 377-402. doi:10.1037/ 0003-066X.58.5.377

Andersen, M.B. (1993). Questionable sensitivity: A comment on Lee and Rotella. The Sport Psychologist, 7 , $1-3$.

Andersen, M.B. (Ed.). (2005). Sport psychology in practice. Champaign, IL: Human Kinetics.

Brah, A. (1996). Cartographies of diaspora: Contesting identities. London: Routledge.

Brislin, R.W., Lonner, W.J., \& Thorndike, R.M. (1973). Cross-cultural research methods. New York, NY: John Wiley.

Bronfenbrenner, U. (1979). The ecology of human development: Experiments by nature and design. Cambridge, MA: Harvard University Press.

Butryn, T.M. (2002). Critically examining White racial identity and privilege in sport psychology consulting. The Sport Psychologist, 16, 316-336.

Butryn, T.M. (2010). Integrating whiteness in sport psychology. In T.V. Ryba, R.J. Schinke, \& G. Tenenbaum (Eds.), The cultural turn in sport psychology (pp. 127-152). Morgantown, WV: Fitness Information Technology.

Dzikus, L. (2012). Shreds of memory: A first person narrative of sexual acquaintance exploitation in a youth sport experience. Athletic Insight, 4, 155-170.

Ganzen, V.A. (1984). Системные описания в психологии [System's descriptions in psychology]. Leningrad: Leningrad University Press.

Garner, S. (2007). Whiteness: An introduction. London: Routledge.

Geertz, C. (1973). The interpretations of cultures. New York, NY: Basic Books.

Gilbourne, D., \& Andersen, M.B. (Eds.). (2011). Critical essays in applied sport psychology. Champaign, IL: Human Kinetics.

Gill, D.L. (1994). A feminist perspective on sport psychology practice. The Sport Psychologist, 8, 411-426.

Gill, D.L. (Ed.). (2001). In search of feminist sport psychology: Then, now, and always [Special Issue]. The Sport Psychologist, 15(4), 363-449.

Gill, D.L. (2007). Integration: The key to sustaining kinesiology in higher education. Quest, 59, 269-286.

Gill, D.P., \& Kamphoff, C.S. (2010). Sport psychology and representation. In T.V. Ryba, R.J. Schinke, \& G. Tenenbaum (Eds.), The cultural turn in sport psychology (pp. 53-74). Morgantown, WV: Fitness Information Technology.

Hall, R.L. (2001). Shaking the foundation: Women of color in sport. The Sport Psychologist, 15, 386-400.

Hanrahan, S.J. (2004). Sport psychology and indigenous performing arts. The Sport Psychologist, 18, 60-74.

Hanrahan, S.J. (2009). Working with Australian aboriginal athletes. In R.J. Schinke \& S.J. Hanrahan (Eds.), Cultural sport psychology (pp. 191-198). Champaign, IL: Human Kinetics. 
Henriksen, K. (2010). The ecology of talent developmnet in sport (Doctoral thesis, University of Southern Denmark, Odense, Denmark).

Hodge, K., Sharp, L.A., \& Ihirangi Heke, J. (2011). Sport psychology consulting with Indigenous athletes: The case of New Zealand Mãori. Journal of Clinical Sport Psychology, 5, 350-360.

International Test Commission. (2010). International test commission guidelines for translating and adapting tests. Retrieved from http://www.intestcom.org

Jarvis, P. (1999). The practitioner-researcher. Developing theory from practice. San Francisco, CA: JosseyBass.

Kamphoff, C.S., Gill, D.L., Araki, K., \& Hammond, C.C. (2010). A content analysis of cultural diversity in the association for applied sport psychology's conference programs. Journal of Applied Sport Psychology, 22, 231-245.

Krane, V. (1996). Lesbians in sport: Towards acknowledgment, understanding, and theory. Journal of Sport and Exercise Psychology, 18, 237-246.

Krane, V., \& Baird, S. (2005). Using ethnography in applied sport psychology. Journal of Applied Sport Psychology, 17, 87-107. doi:10.1080/10413200590932371

Krane, V., Waldron, J., Kauer, K., \& Semerjian, T. (2010). Queering sport psychology. In T.V. Ryba, R.J. Schinke, \& G. Tenenbaum (Eds.), The cultural turn in sport psychology (pp. 153-179). Morgantown, WV: Fitness Information Technology.

Kuhn, T. (1962). The structure of scientific revolutions. Chicago: University of Chicago Press.

Lane, D.A., \& Corrie, S. (2006). The modern scientist-practitioner: A guide to practice in psychology. London: Routledge.

Lee, C.C., \& Rotella, R.J. (1991). Special concerns and considerations for sport psychology consulting with black athletes. The Sport Psychologist, 5, 365-369.

Martin, M., \& Vaughn, B.E. (2007). Strategic diversity \& inclusion management magazine (pp. 31-36). San Francisco, CA: DTUI.

Martins, M.P., Mobley, M., \& Zizzi, S.J. (2000). Multicultural training in applied sport psychology. The Sport Psychologist, 14, 81-97.

Matsumoto, D., \& Jones, C.A.L. (2009). Ethical issues in cross-cultural psychology. In D. Merters \& P. Ginsberg (Eds.), Handbook of social science research ethics (pp. 323-336). Newburg Park, CA: Sage.

McGannon, K.R., \& Johnson, C.R. (2009). Strategies for reflective cultural sport psychology research. In R. J. Schinke \& S.J. Hanrahan (Eds.), Cultural sport psychology (pp. 57-75). Champaign, IL: Human Kinetics.

Miller, J.G. (2002). Bringing culture to basic psychology theory-beyond individualism and collectivism: Comment on Oysterman et al. (2002). Psychological Bulletin, 128, 97-109. doi:10.1037/00332909.128.1.97

Moghaddam, F.M., \& Studer, C. (1997). Cross-cultural psychology: The frustrated gadfly's promises, potentialities, and futures. In D. Fox \& I. Prilleltensky (Eds.), Critical psychology: An introduction (pp. 185-201). Thousand Oaks, CA: Sage.

O’Dell, L., de Abreu, G., \& O’Toole, S. (2004). The turn to culture. The Psychologist, 17, 138-141.

Parham, W.D. (2005). Raising the bar: Developing an understanding of athletes from racially, culturally, and ethnically diverse backgrounds. In M.B. Anderson (Ed.), Sport psychology in practice (pp. 201-215). Champaign, IL: Human Kinetics.

Pettifor, J.L. (1996). Ethics: Virtue and politics in the science and practice of psychology. Canadian Psychology, 37, 1-12.

Pettifor, J.L. (2001). Are professional codes of ethics relevant for multicultural counseling? Canadian Journal of Counseling and Psychotherapy, 35, 26-35.

Pettifor, J.L. (2004). Preferred strategies for learning ethics in the practice of a discipline. Canadian Psychology, 43, 260-269.

Ponterotto, J.G. (2005). Qualitative research in counseling psychology: A primer on research paradigms and philosophy of science. Journal of Counseling Psychology, 52, 126-136. doi:10.1037/00220167.52.2.126

Ram, N., Starek, J., \& Johnson, J. (2004). Race, ethnicity, and sexual orientation: Still a void in sport and exercise psychology. Journal of Sport \& Exercise Psychology, 26, 250-268.

Ryba, T.V. (2009). Understanding your role in cultural sport psychology. In R.J. Schinke \& S.J. Hanrahan (Eds.), Cultural sport psychology (pp. 35-44). Champaign, IL: Human Kinetics.

Ryba, T.V., \& Schinke, R.J. (2009). Methodology as a ritualized Eurocentricism: Introduction to the special issue. International Journal of Sport and Exercise Psychology, 7, 263-274. doi:10.1080/ 1612197X.2009.9671909 
Ryba, T.V., Schinke, R.J., \& Tenenbaum, G. (Eds). (2010). The cultural turn in sport psychology. Morgantown, WV: Fitness Information Technology.

Ryba, T.V., \& Stambulova, N.B. (2013). Turn to a culturally informed career research and assistance in sport psychology. In N.B. Stambulova \& T.V. Ryba (Eds.), Athletes' careers across cultures (pp. 1-16). London: Routledge.

Ryba, T.V., \& Wright, H.K. (2005). From mental game to cultural praxis: A cultural studies model's implications for the future of sport psychology. Quest, 57, 192-212. doi:10.1080/00336297.2005.10491853

Ryba, T.V., \& Wright, H.K. (2010). Sport psychology and the cultural turn: Notes toward cultural praxis. In T.V. Ryba, R.J. Schinke, \& G. Tenenbaum (Eds.), The cultural turn in sport psychology (pp. 1-28). Morgantown, WV: Fitness Information Technology.

Schinke, R.J., \& Hanrahan, S.J. (Eds.). (2009). Cultural sport psychology. Champaign, IL: Human Kinetics.

Schinke, R.J., \& Hanrahan, S.J. (Eds.). (2012). Sport for development, peace and social justice. Morgantown, WV: Fitness Information Technology.

Schinke, R.J., Hanrahan, S.J., \& Catina, P. (2009). Introduction to cultural sport psychology. In R.J. Schinke \& S.J. Hanrahan (Eds.), Cultural sport psychology (pp. 3-11). Champaign, IL: Human Kinetics.

Schinke, R.J., McGannon, K.R., Parham, W.D., \& Lane, A. (2012). Toward cultural praxis: Strategies for self-reflexive sport psychology practice. Quest, 64, 34-46. doi:10.1080/00336297.2012.653264

Schinke, R.J., \& Moore, Z.E. (2011). Culturally informed sport psychology: Introduction to the special issue. Journal of Clinical Sport Psychology, 5, 283-294.

Schinke, R.J., Peltier, D., Hanrahan, S.J., Eys, M.A., Yungblut, H., Ritchie, S., ... Michel, G. (2009). The progressive move toward indigenous strategies among a Canadian multicultural research team [Special issue]. International Journal of Sport and Exercise Psychology, 7, 309-322. doi:10.1080/ 1612197X.2009.9671912

Schinke, R.J., Watson, J.W., Enosse, N., Peltier, D., \& Lightfoot, N. (2010). Cultural missteps and ethical considerations with indigenous populations: Preliminary reflections from Northeastern Ontario, Canada. Journal of Academic Ethics, 8, 233-242.

Schlossberg, N.K. (1981). A model for analysing human adaptation to transition. The Counselling Psychologist, 9, 2-18.

Scott, J.W. (1994). Deconstructing equality-versus-difference: Or, the uses of poststructuralist theory for feminism. In S. Seidman (Ed.), The postmodern turn: New perspectives on social theory (pp. 282-298). Cambridge: Cambridge University Press.

Shweder, R.A. (1990). Cultural psychology—what is it? In J.W. Stigler, R.A. Shweder, \& G. Herdt (Eds.), Cultural psychology: Essays on comparative human development (pp. 1-43). Cambridge: Cambridge University Press.

Si, G.Y., Duan, Y., Li, H.Y., \& Jiang, X. (2011). An exploration into socio-cultural meridians of Chinese athletes' psychological training. Journal of Clinical Sport Psychology, 5, 325-338.

Smith, B., Collinson, J.A., Phoenix, C., Brown, D., \& Sparkes, A.C. (2009). Dialogue, monologue, and boundary crossing within research encounters: A performative narrative analysis. International Journal of Sport and Exercise Psychology, 7, 342-358. doi:10.1080/1612197X.2009.9671914

Spering, M. (2001). Current issues in cross-cultural psychology: Research topics, applications, and perspectives. Universität Heidelberg. Unpublished paper. Retrieved December 5, 2012, from www.psychologie. uni-heidelberg.de/ae/allg_en $/ \mathrm{mitarb} / \mathrm{ms} /$ crosscultural\%20psy.pdf

Stambulova, N.B. (1994). Developmental sports career investigations in Russia: A post-perestroika analysis. The Sport Psychologist, 8, 221-237.

Stambulova, N.B. (2012). Working with athletes in career transitions. In S. Hanton \& S. Mellalieu (Eds.), Professional practice in sport psychology: A review (pp. 165-194). London: Routledge.

Stambulova, N.B., \& Alfermann, D. (2009). Putting culture into context: Cultural and cross-cultural perspectives in career development and transition research and practice. International Journal of Sport and Exercise Psychology, 7, 292-308. doi:10.1080/1612197X.2009.9671911

Stambulova, N.B., Alfermann, D., Statler, T., \& Côté, J. (2009). ISSP position stand: Career development and transitions of athletes. International Journal of Sport \& Exercise Psychology, 7, 395-412. doi:10.1080/1612197X.2009.9671916

Stambulova, N.B., \& Ryba, T.V. (Eds.). (2013a). Athletes' careers across cultures. London: Routledge.

Stambulova, N.B., \& Ryba, T.V. (2013b). Setting the bar: Towards cultural praxis of athletes' careers. In N. B. Stambulova \& T.V. Ryba (Eds.), Athletes' careers across cultures (pp. 235-254). London: Routledge.

Stambulova, N.B., Stephan, Y., \& Jäphag, U. (2007). Athletic retirement: A cross-national comparison of elite French and Swedish athletes. Psychology of Sport and Exercise, 8, 101-118. doi:10.1016/j. psychsport.2006.05.002 
Taylor, J., \& Ogilvie, B.C. (1994). A conceptual model of adaptation to retirement among athletes. Journal of Applied Sport Psychology, 6, 1-20.

Tenenbaum, G., Papaioannou, A., \& Samulski, D. (2003). ISSP position stand: Competencies (occupational standards, knowledge, and practice) and their accomplishment (learning specification, essential knowledge, and skills) in sport and exercise psychology. International Journal of Sport and Exercise Psychology, 1, 155-166. doi:10.1080/1612197X.2003.9671709

Terry, P.C. (2009). Strategies for reflective sport-psychology practice. In R.J. Schinke \& S.J. Hanrahan (Eds.), Cultural sport psychology (pp. 79-89). Champaign, IL: Human Kinetics.

Triandis, H.C. (2004). Cultural syndromes. In C. Spielberger (Ed.), Encyclopedia of applied psychology (Vol. 1, pp. 555-560). New York, NY: Elsevier.

Triandis, H.C., Malpass, R., \& Davidson, A.R. (1973). Psychology and culture. Annual Review of Psychology, 24, 355-378. doi:10.1146/annurev.ps.24.020173.002035

Urry, J. (2000). Mobile sociology. British Journal of Sociology, 51, 185-203.

Van de Vijver, F.J.R., \& Leung, K. (1997). Methods and data analysis of comparative research. In J.W. Berry, Y.H. Poortinga, \& J. Pandey (Eds.), Handbook of cross-cultural psychology, vol. 1: Theory and method (pp. 257-300). Needham Height, MA: Allyn \& Bacon.

Weedon, C. (2004). Identity and culture: Narratives of difference and belonging. Berkshire: Open University Press.

Wright, H.K. (2007). Cultural studies of sport psychology and the formation of a multicultural, socially just sport studies. Diversity lecture delivered at the Association for Applied Sport Psychology Conference, Louisville, KY.

Wylleman, P., \& Lavallee, D. (2004). A developmental perspective on transitions faced by athletes. In M. Weiss (Ed.), Developmental sport and exercise psychology: A lifespan perspective (pp. 507-527). Morgantown, WV: Fitness Information Technology. 